\title{
Green initiative in Suranaree University of Technology in Thailand
}

\author{
Vacharapoom Benjaoran ${ }^{1, *}$, and Patranid Parinyakulset ${ }^{2}$ \\ ${ }^{1}$ School of Civil Engineering, Suranaree University of Technology, Nakhonratchasima, Thailand \\ ${ }^{2}$ Division of Buildings and Ground, Suranaree University of Technology, Nakhonratchasima, \\ Thailand
}

\begin{abstract}
Suranaree University of Technology (SUT) has participated in the Universitas Indonesia (UI) GreenMetric World University Rankings since 2013. It attempts to pursue campus sustainability programs and policies. The rankings is broadly based on the frameworks of environment, economy, and equity. The measurement criteria are divided into six categories with different point weighting i.e. setting and infrastructure, energy and climate change, waste, water, transportation, and education. These criteria heavily and directly involve the tasks and responsibilities of SUT's the Division of Buildings and Ground. A lot of environmental challenges in civil engineering and infrastructure works need to be achieved. The results of this year self-assessment show that although the university is in the developing stage, it can preserve both natural and planted forests more than $90 \%$. It takes seriously role in green initiative by contributing $30 \%$ of total budget on sustainable efforts each year. It receives four national awards in the recognition of energy conservation initiative for green buildings. The university establishes the Integrated Solid Waste Management Plant (ISWM Plant) based on mechanical and biological treatment (MBT) which turns general wastes into valuable and sellable refuse-derived fuel (RDF). Moreover, these sustainable movements are in the continuous improvement process.
\end{abstract}

\section{Introduction}

Not only all universities devoted themselves to academic teaching and research, they are also obliged to play a leading role in the search for solutions to the current challenging problems. Many leading universities in the world are concerned to mitigate the global warming issue and to support campus sustainability through reducing their carbon footprint as much as possible. This worldwide awareness convinced Universitas Indonesia to establish a university world-ranking system in 2010. Instead of using research and educational indicators, it mostly embraced the environmental performances. It aimed to measure the universities' effort including their current environmental conditions and policies and rated the universities' worldwide performance. With respect to this specific intention in sustainability and green campus, the Universitas Indonesia (UI) GreenMetric Ranking of World Universities is the

\footnotetext{
* Corresponding author: vacharapoom@sut.ac.th
} 
first attempt to make a global ranking of universities' sustainable behavior (Grindsted 2011). It was an online and open access system which is designed to be suitable for universities in both developed and developing countries.

Suranaree University of Technology (SUT) in Thailand is very enthusiastic toward environmental sustainability. It has announced one of the principal development policies on Green and Clean University since it was founded in 1994. SUT campus is situated in a degraded national forest reserve in the northeast of Thailand. Therefore, it is eager to gradually increase green space and enhance a quality of life on the campus. The success of the green and clean policy is evidenced by a number of national recognitions and awards for example, the Green Office award recently given by the Department of Environmental Quality Promotion, Ministry of Natural Resources and Environment, Thailand, with an excellence (gold) level to the office building of the Division of Buildings and Ground in 2015, and with a good (bronze) level to Surapat 1 building in 2016.

The Green and Clean University policy at SUT is actually aligned with sustainability movement and the UI GreenMetric World University Ranking. To evaluate the performance of policy implementation, thus in 2013 SUT has decided to participate in the UI GreenMetric World University Ranking and was ranked 75th in the world or 8th in Thailand (SUT 2017). Later, with a continuous improvement and development of the university for three years, in 2015, SUT was ranked 52th in the world or the second in Thailand. SUT is willing to maintain a commitment to be the green and clean university and moving forwards to sustainable university.

This paper aims to report achievements and challenges in a frame of UI GreenMetric criteria during year 2016-17. The following sections describe a review of sustainability in higher education, the methodology of UI GreenMetric Ranking system, the results of achievements and challenges at SUT.

\section{Green initiatives in higher education institutes}

Recently, many universities around the world devote themselves to integrate environmental management and sustainability with their development operations. Universities have a direct responsibility to lead their societies through teaching and research to solve or remedy current global environmental problems. They are highly expected to be a role model on sustainable development (León-Fernández and Domínguez-Vilches 2015). Nonetheless, universities can be considered as small cities due to their community's size which have an impact on the environment around the campuses (Lauder et al. 2015). For academic institutions, the Stockholm Declaration of 1972 addressed the Sustainability in Higher Education (SHE). The declaration focused on finding ways in which universities, their leaders, lecturers, researchers, and students can engage their resources in responding to the challenges of balancing between the human quest for economic and technological development with environmental preservation (Tiyarattanachai and Hollmann 2016). During the past 30 years, sustainable universities have been an important issue. Grindsted (2011) examined sustainability in higher education (SHE), specifically in respect to warn about deterioration of the environment, resource scarcity and the need of for sustainability. At present, more than 1400 universities worldwide have signed a SHE declaration. The concept of SHE was then widely been used to figure out the existing situation of the university in terms of sustainability, not only in western universities but also in Asia (Saadatian et al. 2009). Numerous initiatives were taken to integrated sustainable development concepts into university efforts designed to help change society from an unsustainable to a sustainable path. Many universities around the globe put a lot of efforts in implementing changes in campus planning, construction, management and operations in order to transform them into "Green Universities" (Wang et al. 2013). 
Foo (2013) pointed that higher education is a unique intellectual contributor to society's efforts to achieve sustainability, through the practices of skills, consultancies, trainings, and exchange of knowledge. University researchers are the first alarms to alert the environmental challenges, and assist to spearhead a multidisciplinary of technical solutions. He described the historical evolution of environmental higher education in Malaysia. Geng et al. (2013) stated that the local universities should play an active role on moving towards an eco-city and to create a green university. All the faculties, staff members and students must join such an effort. They proposed a model aiming to manage all the campus activities on a sustainable basis. It addresses all the issues related with one university's metabolism and ensures that the views and goals of different stakeholders are considered together. A case study of Shenyang University was chosen due to its unique feature and data availability. Various efforts at SU are detailed, such as the application of ground source heat pump, wastewater recycling at the campus level, integrated solid waste management, green education and research. Jain et al. (2013) reported the implementation of sustainable development at TERI University through higher education and research. An example of its flagship postgraduate program in Environmental Studies and Resource Management has been illustrated. The program is built by seamless integration of sustainability concept that incorporates social, cultural, economic, scientific, technological, legal, and policy perspectives to address issues related to environment and resource management by laying strong emphasis on experimental/empirical evidence. The curriculum has been designed by seamlessly integrating the principles of sustainable development in an interdisciplinary framework. León-Fernández and Domínguez-Vilches (2015) analysed trends in implementing the main initiatives in the field of environmental management and sustainability in Spanish universities, taking as a reference point the guidelines adopted by a number of universities in countries most committed to sustainable development. They found that the Spanish universities follow international trends by applying a variety of environmental management and sustainability tools and carrying out other activities related to the environment and sustainable development. In Brazil, Jabbour et al. (2013) analysed business schools incorporating environmental management issues into their core activities, defined through teaching, research, outreach and management. Two case studies were conducted at Brazilian business schools. They found that the incorporation of environmental management issues tends to begin with researching and teaching and this depends on the personal motivation of few or single faculty researchers. However, the result showed that there are barriers to organizational change towards green business schools and institutional entrepreneurs are important to the process of greening.

\section{UI green metric methodology and criteria}

Universitas Indonesia (UI) initiated a world university rankings in 2010, later known as UI GreenMetric World University Rankings, to measure campus sustainability efforts. It was intended to create an online survey to portray sustainability programs and policies in universities around the world. The objectives of the rankings aim to contribute to academic discourses on sustainability in education and the greening of campuses; to promote university-led social change with regard to sustainability goals. It can also be a tool for selfassessment on campus sustainability for higher education institutions (HEIs) around the globe. The self-assessment report helps inform governments, international and local environmental agencies, and the society about sustainability programs on the campus. All universities in the world with strong commitment to sustainability issues are encouraged to participate in the annual UI GreenMetric World University Rankings. This is because the university's performance aspects (research, education, and environmental protection) are interconnected and multidimensional. 
UI developed their ranking instrument based on the sustainable development concept that encompasses the three Es mutual reinforcing pillars: Environment, Economics and (Social) Equity (Suwartha and Sari 2013). The ranking criteria includes the collection of a basic information of the university such as the size and type of location, whether urban, suburban, or rural. This aims to evaluate the degree of green space and the utilization of the campus space for greenery. The next category concerns energy consumption and its direct link to the carbon footprint. Then the criteria assesses the waste, water utilization, transportation management. Lastly, it aims to evaluate about how the university is involving with the environment and sustainability issue through academic courses, actions, and research funding. Six main criteria of UI GreenMetric World University Ranking were determined based on information provided by respective universities that demonstrates commitment to going green and being sustainable, namely environmental settings and infrastructure, energy and climate change, waste, water, transportation, and education. Categories and weighting of points for year 2016-7 are shown as follows (UI GreenMetric's Guideline 2017).

Table 1. Categories used in the ranking and their weighting.

\begin{tabular}{|l|l|c|}
\hline No & Category & Weighting percentage of total points (\%) \\
\hline 1 & Setting and Infrastructure & 15 \\
\hline 2 & Energy and Climate Change & 21 \\
\hline 3 & Waste & 18 \\
\hline 4 & Water & 10 \\
\hline 5 & Transportation & 18 \\
\hline 6 & Education & 18 \\
\hline & Total & $100 \%$ \\
\hline
\end{tabular}

Scoring for each item will be numeric so that data can be processed statistically. Scores will be simple counts of things, or responses on a scale of some sort. The weighting of six criteria are as shown in Table 1. Each of the criteria will be categorized in a general class of information and when the results are processed the results, the raw scores will be weighted to give a final calculation.

\section{Results}

SUT has carried out activities and tasks according to the UI GreenMetric World University Ranking criteria during 2016-7. Four of the six categories are directly related to civil engineering works. The details are described as follows:

\subsection{Energy and climate change management}

SUT takes an environment initiative role and has rigorously implemented energy conservation measures and policies. In 2017, the university hugely invests in the energy efficient appliances conforming to the Ministry of Energy's standard to replace conventional ones and they are used at the proportion of $82 \%$. The following list is remarkable energy efficient appliances replacements in year 2017: The replacements are split air conditioners for a total of 780,000 Btu, central air conditioners for a total of 3,600,000 Btu, fluorescent T5 or LED lamp with an equivalence of $10,400 \mathrm{kWH} /$ year, and a total of 845 LED street lamps. In addition, SUT invests in the smart building technology which covers over $79 \%$ of total building area, increasing from $72 \%$ from the past year.

SUT is enthusiastic about renewable energy usage. It aims to use different types of renewable energy i.e. bio-diesel prototype plant at the research stage with a capacity of 240 $\mathrm{kW}$; clean biomass power at research prototype stage with a capacity of $100 \mathrm{kWH}$; biogas plant from the university's pig farm of $5 \mathrm{KW}$ or $3,650 \mathrm{kWH} /$ year; solar cell panels installed 
at rooftops of the Division of Buildings and Grounds' office building, student dormitory, Sirindhorn Wissawaphat Building, jogging track around reservoir, and the Integrated Solid Waste Management Plant (ISWM Plant)'s office building with a total capacity of $19.50 \mathrm{~kW}$ or $30,180 \mathrm{kWH} /$ year; the gasification power plant at the testing stage with an expected capacity of $1 \mathrm{MW}$ from RDF and $500 \mathrm{~kW}$ from infectious wastes.

Table 2. Electricity consumption in the university.

\begin{tabular}{|l|c|c|c|}
\hline Year & 2015 & 2016 & 2017 \\
\hline Electricity Unit (MWH) & 23,546 & 26,470 & 24,194 \\
\hline Population (people) & 17,797 & 19,997 & 22,199 \\
\hline Area (sq.m.) & 480,741 & 488,908 & 598,783 \\
\hline $\mathrm{kWH} /$ people & 1,545 & 1,324 & 1,090 \\
\hline $\mathrm{kWH} / \mathrm{m}^{2}$ & 50 & 54 & 40 \\
\hline
\end{tabular}

The university through the Division of Buildings and Ground seriously implements Green Building Concepts in their building design works according to Thai's Rating of Energy and Environmental Sustainability (TREES). The university gets awards and recognitions from various prestigious public organizations. The Ministry of Energy has certified energy efficient building designs on 10 construction projects namely Primary Laboratory for Science and Agriculture Technology, Primary Laboratory for Engineering, The Lower North Eastern Convention and Exhibition Hall, Laboratory for Medical and Health Science, Laboratory for Food and Health Technology, The Excellence Center of Medicine, Laboratory for Health Science and Public Health, Pathology Building, Sirindhorn Wissawaphat Building, Surawiwat School Buildings. SUT is also an initiative on the Green Office Certification from the Department of Environmental Quality Promotion of Thailand. Currently, the university implements on four office buildings namely the Division of Buildings and Ground's office building received a gold medal certificate, Surapat 1 building received a bronze medal certificate, and Multi-Purpose building, and Library building are still in the auditing process. The Department of Alternative Energy Development and Efficiency, the Ministry of Energy, has awarded the Building Design's Energy Conservation Awards on six buildings for passing the Building Energy Code of Thailand. There are one building awarded on "Excellence" level, one building on "Very Good" level, and four buildings on "Good" level. The Ministry of Energy has awarded the Thailand Energy Awards 2017 to the university in the category of Energy Supporter among the group of Educational Institute.

SUT participates in the greenhouse gas emission reduction programs. It uses environmentally friendly refrigerant in all air conditioning system, and replaces air conditioners with energy efficient ones. Thailand Greenhouse Gas Management Public Organization gives the Letter of Recognition under the Low Emission Support Scheme (LESS) for SUT's efforts on GHG emission reduction specially its Integrated Solid Waste Management Plant (ISWM Plant) alone can reduce 9,872 tons CO2 eq. /year. Total carbon footprint of SUT which is (Total Emission per Year) divided by (Open Space Area per Total People) is equal to 47 Tons $\left(\mathrm{CO}_{2}\right.$ eq. $)$, reducing from 49 Tons $\left(\mathrm{CO}_{2}\right.$ eq.) last year.

\subsection{Waste management}

SUT is currently implementing an efficient waste management system. SUT establishes many policies and completely include four action programs into the waste management system i.e. reduce, reuse, recycle, and refuse.

For the reduction and reuse programs, it attempts to reduce the use of paper and plastic within the campus. There are many proactive policies i.e. the announcement on officesupplies conservation policy, implementation on SUT E-Meeting and SUT E-Documentation 
systems, a total ban on foam food containers, "Bring My Lunch Box", "Bring My Cup" and "Reuse Garbage Bag" campaigns, and "SUT Say No Plastic Bag" Campaign.

For the recycle program, SUT establishes effective and incentive programs to recycle wastes within the university. Since the recyclable wastes are valuable, they are separated at the origin and sold to the recycle shop sponsored by the university. The rest are common solid waste which are collected and further treated through the university-owned Integrated Solid Waste Management (ISWM) Plant. The ISWM Plant can prepare and convert these common wastes into valuable organic fertilizer and refuse-derived fuel (RDF). All common solid wastes within the university are around 1,350 tons per year. They are a mix of organic and inorganic non-recyclable wastes (including plastic) that will continue to the next process based on mechanical and biological treatment or MBT. It consists of waste sorting belt system, size reduction shredding, composting system and sieving machine to sort out organic fertilizer and plastic. These processes can turn common wastes into valuable and sellable products. The byproducts can be resulted from the treatment process are such as organic fertilizers, A Grade RDF, B Grade RDF, Mixed Grade RDF, and soil reconditioning material. These byproducts created return money deposited onto the university's environmental fund around $725,983 \mathrm{Baht} / \mathrm{year}$. RDF is used as material to produce pyrolysis oil, which was subsequently used as fuel for vehicles in the university. The organic fertilizer was used to replace chemical fertilizer in the university and nearby communities. This waste management system can completely maximize values of wastes in SUT. Nowadays, the model of SUT waste management has been widely adopted for waste management in many municipalities in Thailand.

At the present, all solid wastes in the university is recycled at $96.24 \%$. Only a tiny $3.76 \%$ are hazardous wastes which including infectious wastes from the SUT's hospital 51,741 kg. per year, electronic toxic wastes $5,210 \mathrm{~kg}$. per year from all disposal electronic appliances, and chemical toxic wastes accounts for $2,902 \mathrm{~kg}$. per year from laboratory. The university professionally treats all these hazardous wastes using different methods regarding types of toxic wastes. For both electronic and chemical toxic wastes are sent out to be treated by a private waste management company. In addition, hospital infectious wastes are treated at the university own Infectious Waste Management Power Plant which is developed from research and scaled up to a prototype plant in 2016 using the gasification technology with an expected capacity of $500 \mathrm{~kW}$. This plant now is not only used for infectious waste disposal from SUT hospital but also from other hospitals in the region.

Table 3. Summary of the university's all wastes treatment process.

\begin{tabular}{|l|r|r|}
\hline Waste at treatment process & \multicolumn{1}{|c|}{$\begin{array}{c}\text { Quantity } \\
\text { (kg./year) }\end{array}$} & $\begin{array}{c}\text { \% of } \\
\text { Total }\end{array}$ \\
\hline All wastes & $1,591,567$ & 100.00 \\
\hline Food scraps & 5,000 & 0.31 \\
\hline Toxic electrical and chemical wastes & 8,112 & 0.51 \\
\hline Infectious wastes & 51,741 & 3.25 \\
\hline Recycle wastes & 175,722 & 11.04 \\
\hline Leftover general wastes & $1,350,992$ & 84.88 \\
\hline - A Grade RDF & 1,712 & 0.11 \\
\hline - B Grade RDF & 65,760 & 4.13 \\
\hline - Mixed Grade RDF & 300,960 & 18.91 \\
\hline - Soil improvement material and organic fertilizers & 301,320 & 18.93 \\
\hline - Moisture & 681,240 & 42.80 \\
\hline Reusable (recyclable) wastes & 850,474 & 96.24 \\
\hline Non reusable wastes & 741,093 & 3.76 \\
\hline
\end{tabular}




\subsection{Water management}

The university operates its own three water production systems and distributes this water through the pipe network for consumption within the campus. The first system is the waterworks plant sourced from raw water from all reservoirs, producing 1,256,080 cu.m. per year. The second system is the groundwater purifying system sourced from three groundwater wells within the campus, producing 2,171 cu.m. per year. Lastly, the wastewater recycling plant sourced from the wastewater collecting pipe system, producing 393,442 cu.m. per year. All three water production systems produces a total of piped water 1,651,693 cu.m. per year and this water is all consumed within the campus.

SUT is much concerned about water supply because it is situated on the large north-east plateau of Thailand. It typically is a sandy soil terrain which has a poor water holding capacity. It usually suffers from lack of water supply during dry season. The university implements several programs regarding water conservation. They are such as 1,690 water meters installation for usage monitoring, preventive maintenance and rapid repair for water pipe network, "Save Our Water" awareness raising campaign, rainwater harvesting system installation, purifying system for groundwater, main reservoir capacity expansion, new minor reservoirs within the campus, raw water pipeline improvement, and water seepage reduction in the reservoir.

Apart from those water supply programs, the university seriously implements the water recycling programs as an effective remedy to raw water deficiency. It has installed a separate water recycling plant and a separate recycled water pipe network. At the present, the university can recycle as much as $31 \%$ of total piped water distributed from the waterworks plant.

The university has a specific pipe network system to collect wastewater from residential, office, and academic zones to its own water recycling plant. These wastewater flows by the gravity and enter into the wastewater recycling plant which is located at the lowest ground level of the campus area. Also, the university has its own biological wastewater treatment system. The treatment includes several processes. After wastewater collected from the main wastewater pipe system, it will flow into different ponds in sequence, the facultative pond, the oxidation pond, the water hyacinth pond, and maturation pond. The treated water will finally go into the wastewater recycling plant which will further treat water similar to the process at the waterworks plant. Each year this biological sewerage treatment system operate a total of 472,104 cubic meters which accounts for almost all of wastewater. Currently the plant can recycle 393,442 cubic meter per year. The treated water was analyzed before and after the treatment. The quality of the recycled water meets the standard and it is good enough for restroom use and gardening through a separate pipe network. The quantity of recycled water used accounts for $31 \%$ of the total water supply. Recycled water is used for garden sprinkler system at 9 buildings and outdoor gardening taps at 15 buildings. Currently recycled water is mainly used for toilet flush at restrooms in 73 buildings or about $60 \%$ of all buildings. Also, recycled water is used in cooling system at the central library building.

Another innovative water recycling program is the sludgy water recycling in the tap water production process at the waterworks plant. In the tap water production process, the plant creates sludgy water from the sedimentation of raw water (thick sludgy water) and the cleaning of filtering sand of the plant (light sludgy water). Both sludgy water accounts for $13 \%$ of the total raw water fed into the production process. It was used to be discharged before but at the present it is collected and recycled back into the production process. 
Table 4. Water consumption within the university.

\begin{tabular}{|l|r|r|}
\hline Item & Usage Quantity (cu.m. / year) & \multicolumn{1}{c|}{$\%$} \\
\hline Water supply (tap water) (treated) & $1,256,080$ & 71.45 \\
\hline Groundwater (treated) & 2,171 & 0.12 \\
\hline Recycled water (treated) & 393,442 & 22.38 \\
\hline Agricultural and gardening water & 106,400 & 6.05 \\
\hline Total treated water usage & $1,256,080$ & 71.45 \\
\hline Total water usage & $1,758,093$ & 100.00 \\
\hline
\end{tabular}

\subsection{Transportation}

SUT is situated in a suburban area with a large size of land. The university campus was not originally planned and designed to encourage non-motorized transport on campus. The land use and the transport system of the university resemble the concept of the sub-division development in the U.S. That is, the campus is divided into zones, each of which is a significant distance from the others; therefore, the university population tend to own and use their personal vehicles. The university has to provide some parking area nearby each building. However, unlike other universities, the university does not allocate privilege parking area for executives to limit parking space to the minimum. SUT has established a policy to reduce the use of personal cars in the campus and promote the carpooling and the use of free service bus instead to reduce traffic and limit parking area. The vehicle access the campus was strictly controlled, requiring registration and display of vehicle pass card. Moreover, the university has provided 16 shuttle buses with a free service for accommodating both students and staff. Also, riding bicycle and walking are promoted by constructing new bicycle lanes and pedestrian roofs, covering a total length 22,700 meters and 2,500 meters, respectively. In addition, there is a rental service for bicycle with free of charge between each building under coral gold bike project. Currently, there are 246 bicycles available.

The average number of all cars entering daily based on a balanced sample, taking term and holiday periods; using CCTV playback analysis. It is noted that SUT has not only the academic activities but also it hosts five social enterprises (i.e. Technopolis, SUT Farm, Surasammanakhan Hotel, Surawiwat School, and SUT Hospital) which significantly cause a number of entering cars. SUT also hosts many events (e.g. national sports) held by external organizations. The number of enrolled students and staff increases by $13 \%$ from the past year. The number of hospital patients (120-bed-hospital) is 212,785 , increasing by $10 \%$ from the past year.

Table 5. Number of vehicles entering the university.

\begin{tabular}{|l|c|c|c|}
\hline Year & 2015 & 2016 & 2017 \\
\hline Average cars per day & 3,152 & 3,533 & 3,485 \\
\hline Average motorcycles number per day & 2,407 & 3,746 & 3,861 \\
\hline
\end{tabular}

Since the university is located on a vast area with a few slopes and small hills, it is difficult to operate an efficient shuttle bus system, and it is quite challenging to reduce the use of personal vehicles and the parking area. However, it is ambitious to promote a use of bicycles and walking. The university puts effort and heavily invests on transportation initiatives to limit or decrease private vehicles on campus.

Car sharing and shuttle bus services programs are promoted. SUT rents most of its cars through contracts and provides pool services for daily operations in order to discourage a use of private cars in the campus. It also supports a use of clean and alternative fuel on these rental cars, such as electrical shuttle buses, cars with hybrid CNG and gasoline fuel. These cars operate on regular routes and timetables during rush hours and on demand or request 
during off-peak hours. A fleet of nine sedans (powered by alternative E20 and CNG fuel) and 3 four door pick-up trucks are provided and shared for staffs only. Moreover, it provides shuttle services with various types of vehicles including 10 electrical shuttle buses, 6 diesel minibuses, 1 diesel bus, 5 diesel vans, and 3 electrical 6-seats-carts for its students and staffs free of charge. All of them are also rental. Their operating time table are scheduled so as to suite itinerary at differing periods, which helps to avoid the use of personal vehicle, and to opt for public transports instead.

SUT has a terminal bus station on campus which is used as a hub station for both inside and outside buses. Some private local buses operate from the university inbound and outbound to the city center of Nakhon Ratchasima. This terminal bus station is also used for all types of shuttle buses servicing inside the campus and as a charging station for all electrical buses. The university provides and financially supports various types of sharing cars and shuttle buses. All these are free services for all university population. There is an estimation of 6,638 passenger-trip/day.

\section{Conclusions}

SUT has strong commitment to pursue a leading green and clean university since the beginning. It has voluntarily participated in the UI GreenMetric World University Rankings for five years. The success of green initiatives are such as environmental friendly development which can rigorously reserve green area at a high rate of more than $90 \%$. It implements the Green Building concept and energy conservation building design for the campus's new building construction. The university can effectively and efficiently manage waste and water through its self-sufficiency. It can recycle more than $95 \%$ wastes from within the campus and nearby community. Also, it recycles water at around $30 \%$ of water usage. To achieve these, the university heavily invested on its own infrastructures, equipment, and research funding.

However, some challenges yet exists and must be overcome in the very near future. In the past the university had more focus on the 'hard' side or the physical development. The 'soft' side or the people involvement should be taken care of. Environmental awareness of all students and staffs are the key to successfully sustain those green efforts. More education and campaigns on environment and sustainable development should be done. This people involvement can enhance the reduction and reuse of resources even more. Smart mobility on public transportation and shuttle services is the most important challenge in order to reverse the current trend of personal vehicle usage. Smart energy or renewable energy is another challenge. SUT is seeking to harvest solar energy from rooftop panels and floating farm through the public-private partnership projects. It is anticipated that the university could reduce its carbon footprint by $30 \%$ in the next two years.

\section{References}

1. Universitas Indonesia (UI). 2017. “Guideline UI GreenMetric World University Rankings 2017" available on http://www.greenmetric.ui.ac.id/

2. Foo, K. Y. 2013. "A Vision on the Role of Environmental Higher Education Contributing to the Sustainable Development in Malaysia." Journal of Cleaner Production, 61:6-12.

3. Geng, Yong, Kebin Liu, Bing Xue, and Tsuyoshi Fujita. 2013. "Creating a 'green University' in China: A Case of Shenyang University." Journal of Cleaner Production, 61:13-19. 
4. Grindsted, Thomas. 2011. "Sustainable Universities - From Declarations on Sustainability in Higher Education to National Law." SSRN Scholarly Paper ID 2697465. Rochester, NY: Social Science Research Network.

5. Jabbour, Charbel José Chiappetta, Joseph Sarkis, Ana Beatriz Lopes de Sousa Jabbour, and Kannan Govindan. 2013. "Understanding the Process of Greening of Brazilian Business Schools." Journal of Cleaner Production, 61:25-35.

6. Jain, Suresh, Preeti Aggarwal, Neeraj Sharma, and Prateek Sharma. 2013. "Fostering Sustainability through Education, Research and Practice: A Case Study of TERI University." Journal of Cleaner Production, 61:20-24.

7. Lauder, Allan, Riri Fitri Sari, Nyoman Suwartha, and Gunawan Tjahjono. 2015. "Critical Review of a Global Campus Sustainability Ranking: GreenMetric.” Journal of Cleaner Production, 108:852-63.

8. León-Fernández, Yolanda, and Eugenio Domínguez-Vilches. 2015. "Environmental Management and Sustainability in Higher Education: The Case of Spanish Universities." International Journal of Sustainability in Higher Education 16 (4):440-455.

9. Saadatian, Omidreza, E. Salleh, O. Tahir, and Kamariah Dola. 2009. "Observations of Sustainability Practices in Malaysian Research Universities: Highlighting Particular Strengths." Pertanika Journal of Social Sciences \& Humanities 17 (2):225-244.

10. Suwartha, Nyoman, and Riri Fitri Sari. 2013. "Evaluating UI GreenMetric as a Tool to Support Green Universities Development: Assessment of the Year 2011 Ranking." Journal of Cleaner Production, 61:46-53.

11. Tiyarattanachai, Ronnachai, and Nicholas M. Hollmann. 2016. "Green Campus Initiative and Its Impacts on Quality of Life of Stakeholders in Green and Non-Green Campus Universities.” SpringerPlus 5 (1):84.

12. Wang, Yutao, Han Shi, Mingxing Sun, Donald Huisingh, Lars Hansson, and Renqing Wang. 2013. "Moving towards an Ecologically Sound Society? Starting from Green Universities and Environmental Higher Education." Journal of Cleaner Production, $61: 1-5$.

13. Suranaree University of Technology. 2017. "Activity and Project" available on http://green.sut.ac.th 